\title{
Alfred Marshall e as "evoluções" vitorianas: situando Darwin e Spencer nos fundamentos teóricos do pensamento marshalliano
}

Manuel Ramon Souza Luz Doutorando em Teoria Econômica, IE/Unicamp, Bolsista CNPq.

Paulo Sérgio Fracalanza Professor Doutor, IE/Unicamp.

\section{Palauras-chave:}

Marshall, Darwin, Spencer, economia evolucionária, progresso, equilíbrio.

Classificação JEL B13, B15, B52.

\section{Key-words \\ Marshall, Darwin, Spencer, evolutionary economics, progress, equilibrium.}

JEL Classification B13, B15, B52.

\section{Resumo}

Partindo de um estudo comparativo entre as visóes teóricas de Charles Darwin e Herbert Spencer sobre os processos de mudança, este artigo procura entender como a gênese dessas ideias acerca da evolução influenciou o pensamento econômico de Alfred Marshall. Nesse sentido, num primeiro momento apresentamos como Darwin e Spencer construíram abordagens completamente distintas e inconciliáveis para entender os fenômenos de mudança em sistemas complexos. A seguir, buscaremos entender como Marshall absorveu essas elaboraçóes vitorianas sobre a evolução dentro de seu construto teórico. Assim, focando nossa investigação nos Principles (1890) e trabalhando com as ideias ali contidas sobre mudança, progresso, equilíbrio e firma representativa, buscaremos assinalar que Marshall seguiu um código de ciência caracterizadamente spenceriano, em que sua abordagem, muitas vezes interpretada como "evolucionária", não apresenta contradição ou incompatibilidade com uma perspectiva fundada no essencialismo neoclássico.

\section{Albstract:}

Starting from a comparative study of the theoretical views of Charles Darwin and Herbert Spencer on the processes of change, this paper seeks to understand how the genesis of these ideas about evolution influenced the economic thought of Alfred Marshall. In this sense, we first present how Darwin and Spencer built completely different and irreconcilable approaches to understanding the phenomena of change in complex systems. Subsequently, we try to understand how Marshall absorbed these Victorians elaborations about evolution within his own theoretical construct. Thus, focusing our investigation on Principles (1890) and working with the ideas contained therein about change, progress, equilibrium and representative firm, we seek to show that Marshall followed a code of science characteristically Spencerian, where his approach, often interpreted as "evolutionary," presents no contradiction or incompatibility with a perspective based on neoclassical essentialism. 


\section{1_Introdução}

O estágio atual do pensamento econômico tem sido caracterizado por uma marcante profusão de elaboraçóes de cunho evolucionário. Apesar de algumas vezes cumprir a função de mero recurso retórico, a retomada de uma ideia de "economia evolucionária”, afastada dos pressupostos teóricos neoclássicos, apresenta-se cada vez mais como uma alternativa factível e consistente para analisar o mundo econômico.

Nesse sentido, entendemos que a construção de uma "economia evolucionária" deve manter referência constante aos desdobramentos históricos do próprio pensamento evolucionário. Compreendemos, assim que manter uma relação de proximidade com a história das ideias evolucionárias constitui uma ferramenta importante para a construção de uma perspectiva de "economia evolucionária" profícua, uma vez que esse processo pode contribuir para a elucidação de recorrentes entraves gerados no campo da teorização econômica.

Apesar de nos dias de hoje estar fortemente sedimentado sobre os princípios definidos, o pensamento evolucionário darwiniano percorreu um longo percurso histórico - tendo enfrentado teorias rivais e buscando sanar suas próprias insuficiências - para finalmente constituir-se como a teoria científica válida para compreender a mudança no mundo vivo. Entender os caminhos, muitas vezes tortuosos e contraditórios, que levaram à proeminência atual da abordagem darwiniana não somente colabora para uma compreensão das aberturas e limites teóricos de tal perspectiva, mas também fornece ao pesquisador em economia importantes pistas acerca de como a própria história do pensamento econômico foi permeada pelos ricos debates gerados em torno das ideias acerca da "Evolução".

O presente trabalho procura contribuir com a perspectiva levantada acima, restringindo-se aqui à verificação de como um estudo comparativo entre as teorias de Charles Darwin e Herbert Spencer acerca dos processos evolucionários pode ajudar entender as construçóes teóricas de outro eminente vitoriano: Alfred Marshall. Dessa forma, o trabalho buscará, num primeiro momento, centrar-se na análise dos fundamentos metodológicos e filosóficos que sustentam e diferenciam as perspectivas darwinianas e spencerianas sobre a "Evolução”. Num segundo momento, o artigo irá verificar como os desenvolvimentos teóricos desses autores afetaram as ideias de Alfred Marshall, retendo nossos esforços na compreensão dessas influências sobre os Principles (1890), focando 
principalmente nas ideias de mudança, progresso, equilibrio e firma representativa. Nesse sentido, a ênfase dada aqui recairá na forma como Marshall (1890), mesmo reconhecendo os elementos que compóem u ma abordagem populacional darwiniana acerca das firmas, opta por construir uma perspectiva evolucionária específica, que se assenta sobre componentes metodológicos e filosóficos que podem ser associados a uma ideia spenceriana de "Evolução".

\section{2_O século XIX e suas dissonantes interpretações acerca da evolução}

A compreensão dos fundamentos teóricos e metodológicos das obras de Charles Darwin (1809-1882) e Herbert Spencer (1820-1903) é de grande importância para qualquer estudo que se dedique a entender a gênese do pensamento evolucionário do século XIX. Para a História do Pensamento Econômico esse esforço de identificação das ideias se justifica, uma vez que esses pensadores estabeleceram visóes amplamente influentes, inclusive para as ideias econômicas, a respeito da dinâmica dos processos evolutivos.

As perspectivas evolucionárias de Darwin e Spencer são radicalmente distintas e desempenharam diferentes pa- péis na história do pensamento científico. A ideia de processo evolucionário defendida por Darwin aparece, hoje, como o fundamento principal e incontestável de qualquer elaboração da biologia moderna. De maneira oposta, a perspectiva teórica defendida por Spencer não apresenta repercussão alguma no pensamento científico moderno. Se Darwin é celebrado hoje como pai da Teoria da Evolução, Spencer, quando lembrado, é tomado como exemplo de interpretação equivocada acerca dos processos de transmutação dos organismos vivos. Freeman (1974) é enfático em assinalar a distância existente entre os fundamentos teóricos dos autores:

"Lumping together the evolutionary theories of Spencer and Darwin is, in the light of the evidence, unwarranted, for the theories of Darwin and Spencer were unrelated in their origins and markedly disparate in their logical structures" (Freeman, 1974, p. 213).

Todavia, mesmo que Spencer não tenha gerado um pensamento evolucionário atualmente válido para o balizamento da ciência contemporânea, acreditamos que o estudo de suas ideias é inescapável, ao menos por duas razóes. A primeira se liga ao reconhecimento de que a gênese do conceito de evolução não se reduz 
aos trabalhos de Darwin, mas deriva de distintas perspectivas, com suas influências recíprocas e querelas, e mesmo que a vertente spenceriana tenha sido descartada como um sistema explicativo das mudanças em vários domínios, a força de algumas de suas ideias ainda se faz sentir plenamente na atualidade. ${ }^{1}$ A segunda razão é que na esfera da economia, influenciada que foi pelo pensamento evolucionário, essa distinção se torna ainda mais crucial, pois como procuraremos caracterizar, nem todo o pensamento reputado como evolucionário pode legitimamente ser atribuído à corrente darwiniana.

Assim, é mister caracterizar com mais propriedade os conceitos fundamentais dos pensamentos darwiniano e spen- ceriano acerca da evolução, construindo demarcadores fundamentais que nos permitam compreender com clareza os distintos elementos mobilizados por essas teorias.

A compreensão dos fenômenos de transmutação do mundo orgânico através da ideia de Seleção Natural, elaborada pioneiramente por Charles Darwin, foi o combustível de uma verdadeira revolução científica. ${ }^{2}$ A ideia sintética de processo evolucionário, cristalizada em $A$ origem das espécies (1859), constituiu-se num marco para o pensamento científico moderno. Nesse sentido, Huxley (1940) enfatiza a importância da Teoria da Evolução de Darwin para a ciência moderna:

A Teoria da Evolução é, sem dúvida alguma, a generalizaçâo mais importante

$\begin{array}{ll}{ }^{1} \text { É importante ressaltar aqui } & \text { Lamarck e à visão alternativa } \\ \text { que a busca das leis dos seres } & \text { descontinuísta de Cuvier. } \\ \text { vivos possui raízes muito } & \text { 2 Partindo de um ponto de } \\ \text { mais antigas que as ideias } & \text { vista absolutamente vebleniano, } \\ \text { evolucionistas elaboradas } & \text { poderíamos argumentar que a } \\ \text { no século XIX. Para um } & \text { Teoria da Evolução darwiniana } \\ \text { aprofundamento no estudo } & \text { foi marcada por um hábito } \\ \text { destas ideias indicamos Mayr } & \text { mental gerado pela produção } \\ \text { (1982) e Foucault (1966), sendo } & \text { industrial. A esse respeito } \\ \text { que este último traça um } & \text { convém destacar que, segundo } \\ \text { percurso histórico que se } & \text { Veblen (1904, p. 183), a ciência } \\ \text { inicia com a abordagem } & \text { que se inaugura no século } \\ \text { mecanicista do século XVII } & \text { XVIII e que se desenvolve } \\ \text { e assume uma perspectiva } & \text { durante o século XIX é } \\ \text { continuísta a partir do XVIII, } & \text { profundamente marcada pela } \\ \text { chegando ao transformismo de } & \text { transformação do ambiente }\end{array}$

cultural (e dos hábitos de pensamento), convulsionado pela revolução industrial britânica. Na medida em que o avanço tecnológico da maquinaria e da indústria se desdobra, o progresso dos aperfeiçoamentos e invençóes passa a depender cada vez mais da compreensão dos processos tecnológicos em curso e não das explicações fornecidas por um conhecimento escolástico que indagava sobre as causas primárias, os desígnios da natureza, a desejabilidadedos efeitos, ou suas consequências escatológicas (Veblen, 1904). Para Veblen, a compreensão dos processos, vistos como inerentemente complexos, é reconhecida como a chave para o desenvolvimento da ciência evolucionária. Assim Darwin, impregnado por esses hábitos de pensamento, propóese a explicar as mudanças das espécies a partir do processo pelo qual elas se originam, sem recorrer às prime causa que estariam na origem de suas diferenças. 
até agora feita no campo da biologia, digna de emparelhar-se com as grandes concepçöes gerais das ciências físicas tais como a conservação da energia, a moderna teoria atômica ou a teoria da gravitação de Newton (Huxley, 1940, p. 131).

Da mesma maneira, Mayr (2006) destaca que, para além de sua excepcional contribuição às ciências biológicas, o materialismo de Darwin foi responsável por mudar completamente os hábitos mentais dos cientistas modernos:

"Na verdade, exceto por aqueles que se dizem adeptos do criacionismo e que dizem acreditar na verdade literal da Bíblia, podemos dizer que todo o pensador moderno é, em última análise, um Darwiniano" (Mayr, 2006, p. 104).
Vejamos, portanto, quais são as ideias mobilizadas pela perspectiva darwiniana.

A definição moderna de evolução nasce da ideia de "descendência com modificação", apresentada em Darwin (1859). ${ }^{3}$ De maneira sintética, podemos dizer que a teoria da evolução darwiniana funda-se em três pilares essenciais. Esses determinantes básicos estão representados nos princípios de variação, herança e seleção. Para Darwin, todos os processos evolucionários poderiam ser compreendidos através da interrelação de tais princípios dentro de uma perspectiva filosófica guiada pela ideia de causa eficiente e cumulatividade dos fenômenos. ${ }^{4}$ Nesse sentido, e dando ênfase ao papel da Seleção Natural, Darwin apresenta como esse processo pode explicar a vida:

\footnotetext{
${ }^{3} \mathrm{O}$ escopo deste trabalho não pretende fazer uma análise acerca do processo histórico de construção do pensamento darwiniano nas ciências biológicas. Porém, é importante assinalar que a biologia moderna teve dois momentos-chave para o estabelecimento de suas ideias. O primeiro é representado pela gênese do pensamento darwiniano cristalizado de maneira integral em Darwin (1859). O segundo momento se consubstanciou no primeiro

\author{
terço do século XX, quando \\ a genética mendeliana foi \\ darwiniana, formando o \\ que ficou conhecido como \\ Para entender a história \\ do pensamento biológico \\ moderno recomenda-se a \\ (2005), Gould (1982) \\ e Leakey (2007).
} associada à Seleção Natural a "Teoria Sintética da Evolução", que conforma as bases da biologia moderna. leitura de Jablonka e Lamb

${ }^{4}$ Veblen (1898, 1904 e 1906), Dennett (1995) e Hodgson
}
(2004) destacam que Darwin utiliza ativamente a ideia de causa eficiente, ou causalidade, que busca explicar quais seriam as razóes materiais, ou mecânicas, da mudança. Nesse sentido, Darwin rechaça o conceito de causa final, tão difundido na biologia até então, que procurava analisar o propósito ou fim teleológico dos fenômenos. Combinado com essa ideia de causa eficiente, outro componente filosófico fundamental do pensamento darwiniano
é a percepção do poder cumulativo dos processos que se desenrolam em um tempo cronológico. Assim, de forma sintética, podemos dizer que para Darwin os resultados complexos podem ser explicados em termos de uma sucessão detalhada de eventos dados por uma acumulação de sucessivos mecanismos causais eficientes. Essa é a razão que faz Mayr (2000, p.80) apontar que Darwin introduziu a ideia de historicidade nas ciências biológicas.




\begin{abstract}
A Seleção Natural procura, a cada momento e em todo o mundo, as variaçôes mais insignificantes, rejeitando as nocivas (para o indivíduo), preservando $e$ ampliando as que forem uiteis, trabalhando de forma silenciosa [...] Para que as transformaçôes importantes se produzam em uma espécie, é necessário que uma variedade, uma vez formada, apresente-se de novo, talvez após longos séculos. Por outro lado é necessário que essa variedade se conserve e se renove (Darwin, 1859, p. 146-147).
\end{abstract}

Para Darwin (1859), portanto, a "Evolução" é compreendida como um processo causal e cumulativo que se desenvolve em um tempo cronológico. Nessa mesma direção, é interessante ver que a definição moderna de evolução, extraída de um de seus maiores expoentes modernos, o zoólogo Richard Dawkins, além de não se opor à perspectiva de Darwin, está completamente fundada em seus princípios: "evolution, at bottom, consists of the changing frequencies of genes in gene pools" (Dawkins, 2008, p. 27). Ora, a variaçấo da frequência dos genes em uma população de genes não é nada além de um processo temporal no qual genes variam, são selecionados e herdados, alterando sua frequência com relação a um período anterior. Torna-se evidente, portanto, que os princípios de variação, seleção e he- rança, desenvolvidos por Darwin, estão integralmente presentes na concepção de "Evolução" da biologia moderna.

De maneira completamente oposta a essas ideias, a concepção de "Evolução" cunhada por Spencer não compartilha de nenhuma das visóes teóricas de Darwin (1859). 5 Em seu mais relevante livro, First Principles (1862), Spencer já nos mostra essa distância em relação ao pensamento darwiniano através de sua famosa definição:

"Evolution is definable as a change from an incoherent homogeneity to a coherent heterogeneity, accompanying the dissipation of motion and integration of matter" (Spencer, 1862, p. 71).

$\begin{array}{ll}\text { Eale assinalar que as teorias } & \text { por assim dizer-nada menos } \\ \text { evolucionistas de Spencer, } & \begin{array}{l}\text { de } 368.755 \text { exemplares de suas } \\ \text { obras haviam sido vendidas." } \\ \text { apesar de não possuírem }\end{array} \\ \text { uma influência direta sobre o } & \text { (Galbraith, 1977, p.37). Taylor } \\ \text { pensamento científico atual, } & \text { (1996) ressalta a influência } \\ \text { tiveram grande repercussão } & \text { de Spencer sobre os cientistas } \\ \text { durante a era vitoriana. } & \text { sociais britânicos de meados } \\ \text { Hodgson (1998, p. xiii) } & \text { do século XIX: "Spencer's } \\ \text { destaca que o prestígio de } & \text { influence was probably at its } \\ \text { Spencer, no final do século } & \text { greatest among the generation } \\ \text { XIX, era provavelmente maior } & \text { of British social scientists who } \\ \text { que o de Darwin. Segundo } & \text { followed the Victorian era, } \\ \text { Galbraith (1977), a fama de } & \text { many of whom developed their } \\ \text { Spencer não se restringia à } & \text { own positions in relation to } \\ \text { Inglaterra: "Em toda parte dos } & \text { his, and often incorporated key } \\ \text { Estados Unidos, nos quarenta } & \text { Spencerian ideas and concepts } \\ \text { anos que se seguiram a 1860 - } & \text { in their work" (Taylor, 1996, } \\ \text { isto é, antes do aparecimento } & \text { p. xvii-xviii). }\end{array}$


Essa simples definição cristaliza todo o sistema ontológico-teórico desenvolvido por Spencer para explicar qualquer tipo de processo evolutivo. ${ }^{6}$ Nesse sentido, uma cuidadosa incursão sobre os aspectos fundamentais do pensamento spenceriano deve buscar decifrar a função de cada elemento levantado pelo seu conceito específico de evolução, realizando a comparação necessária, com vistas aos fins desse trabalho, à perspectiva evolucionária darwiniana.

Inicialmente é necessário entender que Spencer (1862) distingue claramente as chamadas "leis fenomênicas" das "leis fundamentais". As leis fundamentais conformam o conjunto de explicações dadas pela física de seu tempo e que, em última instância, regulariam todos os fenômenos do universo. De maneira distinta, as leis fenomênicas especificavam o curso da transformação da matéria provocado pelas leis fundamentais. Assim, as leis fe- nomênicas seriam leis associadas e dependentes das leis físicas.

Os processos de mudança no mundo orgânico são interpretados por Spencer (1862) através dessa hierarquia explicativa, na qual as leis da física são protagonistas. A "Evolução" spenceriana é concebida, portanto, como a manifestação direta de determinados princípios físicos universais. Nessa perspectiva, Spencer utiliza ativamente o princípio de conservação da energia, renomeado em sua obra como a lei da persistência da força. Assim, a evolução de Spencer é explicada em última instância como uma decorrência dessa lei física, possuindo dois axiomas fundamentais: a indestrutibilidade da matéria e a existência de um movimento contínuo da força. ${ }^{7}$ Para Haines (1992),

"Spencer developed the law of evolution by considering the phenomena of evolution in terms of matters and motion" (Haines, 1992, p.166).

\footnotetext{
${ }^{6}$ Segundo Taylor (1996a), é esta concepção ontológica de evolução que dá elementos para Spencer expandir sua análise do campo orgânico para o mundo social, "apparently demonstrating that the whole of the cosmos, from nebulae to moral sentiments, obeyed the same general laws" (Taylor, 1996a, p. v).
}

${ }^{7}$ Baiardi (2008, p. $15-$
conservaçáo da energia
fascinava Spencer exatamente
pelo seu poder de síntese,
já que se postulava ser esta
uma lei comum para a
mecânica, a termodinâmica, a
eletricidade e o magnetismo.
Há de se ter em conta que os
estudos sobre conservação

de energia começaram a ser divulgados com os trabalhos de Julius Robert Mayer (1814-1871), em 1842, e um ano depois por James Joule (1818-1889), que calcularam o fator de conversáo entre energia mecânica e térmica. Haines (1992) assinala que os paradigmas da física eram tidos como o eixo condutor

\author{
da ideia de ciência da era \\ vitoriana: "Spencer followed \\ Whewell, Herschel and Mill \\ and accepted Newtonian \\ astronomy as the paradigm \\ of all science, then, like other \\ scientists of his days, he would \\ have felt compelled to interpret \\ his findings in terms of matter, \\ motion and force" \\ (Haines, 1992, p. 169).
}


Também Hodgson (1993) aponta como a física possui um papel dominante na

"Evoluçâa" spenceriana: "For Spencer, Evolution involved the continuous redistribution of matter and motion. Like the ancient atomists, he upholds the constancy of matter and the indestructibility of motion" (Hodgson, 1993, p. 88).

Assim sendo, pode-se interpretar que a "Evolução" de Spencer (1862) não é nada mais do que uma teoria sobre os caminhos pelos quais a lei da persistência $d a$ força se manifesta no mundo vivo. A biologia, nessa perspectiva, é compreendida apenas como uma ciência auxiliar do essencialismo físico, ou seja, a biologia seria uma ciência que deve descobrir as leis fenomênicas que explicam o movimento dado pelas leis fundamentais da física. Para Spencer, a leis biológicas possuem apenas um caráter acessório para o determinismo físico, assim "biological phenomena, and biological laws are derivative, not ultimate" (La Vergata, 1995, p. 147).

$\mathrm{O}$ primeiro ponto relevante a se entender sobre as leis fenomênicas da evolução spenceriana reside no fato de como ela combina a concepção do progressismo embriológico de Von Baer com o mecanismo de mudança lamarckiano. O biólogo alemão Karl Ernst von Baer (1792-1876), partindo da análise do de- senvolvimento de embrióes, descrevia que o processo de alteração das estruturas embriológicas consistia num movimento de diferenciaçôes sucessivas que levaria a um aumento da complexidade estrutural daquele organismo. Assim como um embrião que se desenvolve a partir de algumas células indiferenciadas, até formar estruturas diferenciadas com células desempenhando funções específicas, para esse modelo orgânico a evolução é entendida como um processo de mudança progressiva de estruturas homogêneas, indiferenciadas e sem integração, em direção a estruturas heterogêneas, diferenciadas e integradas.

Foi a partir dessa ideia embriológica que Spencer utilizou pela primeira vez, em O progresso, sua lei e sua causa (1857), o conceito de mudança teleológica em direção a uma complexidade estrutural como um requisito necessário para a evolução:

\footnotetext{
Formulated by constructing an analogy to von Baer's law of individual development, this law specified the course of change in the inorganic and superorganic realms as a change from homogeneity of structure to heterogeneity of structure through a process of successive differentiations and integrations (Haines, 1992, p. 164).
} 
A ideia de "Evoluçáo" como sinônimo de "Progresso", ainda muito presete no senso comum contemporâneo, advém dessa utilização, por parte de Spencer, dos conceitos de desenvolvimento embriológico individual divulgados por Von Baer.

Para Spencer, as leis da mudança do desenvolvimento individual obedeciam a uma única lei a reger toda sorte de mudanças, ou seja, uma "lei geral do progresso”. Uma decorrência da aplicação desse princípio é que ele possibilita a realização de uma hierarquização das estruturas, que em sua abordagem poderiam ser tanto biológicas quanto sociais, nas quais a ordenação é dada por um gradiente de complexidade das estruturas, organizadas progressivamente a partir das mais homogêneas e desintegradas em direção às mais heterogêneas e integradas. ${ }^{8}$ Dessa maneira, realizando uma comparação entre a conformação de distintas estruturas, Spencer conseguia classificar quais seriam as mais evoluídas e quais as menos evoluídas. A abrangência que Spencer dá a essa perspectiva é reveladora:

As investigaçôes de Wolf, Goethe e von Baer comprovam que as mudanças, verificadas com a transformação da semente na árvore e do óvulo no animal, consistem na passagem da estrutura homogênea para a estrutura heterogênea[...] Esta lei do progresso orgânico é a lei de todo o progresso; quer se trate das transformaçôes na terra, do desenvolvimento da vida à sua superficie ou do desenvolvimento das instituiçóes politicas, da indústria, do comércio, da lingua, da literatura, da ciência mediante sucessivas diferenciaçôes. Desde as mais remotas transformaçôes cósmicas, de que ainda existem sinais, até os mais recentes resultados da civilização, vê-se que o progresso consiste essencialmente na passagem do homogêneo para o heterogêneo. (Spencer, 1857, p. 13-14).

Assim, portanto, a Evolução de Spencer é absolutamente teleológica, um

\footnotetext{
${ }^{8}$ Se a Evolução, para Spencer, deve ser entendida como uma

da heterogeneidade, mas, pelo contrário, levassem a uma maior homogeneização dos elementos de uma estrutura? Para esse fenômeno Spencer (1857) utiliza o termo dissolução (ou retrogradação),

ou seja, o oposto à evolução: "In some cases the habits of life adopted being simpler than before, a less heterogenous structure will result: ther will be a retrogradation" (Spencer, 1857, p. 48). 
estado final levado a cabo por uma lei do progresso que se torna evidente pelo aumento da heterogenia e da integração. Hodgson (1993) destaca a ideia central da evolução spenceriana:

"The evolutionary process was seen as a beneficent journey from the lower to the higher form of organization of life, and from the inferior to the superior" (Hodgson, 1993, p.85). ${ }^{\text {? }}$

Para a teoria de Darwin (1859), o progresso spenceriano não possui nenhum papel relevante. Estrutura, homogeneização, heterogenia e integração não fazem parte dos elementos analíticos de Darwin que, como vimos, compreende Evolução, ou descendência com modificação, apenas como um processo de mudança não teleológico. Darwin é enfático em retirar a ideia de progresso de sua concepção evolucionária: ${ }^{10}$

Pela nossa teoria, a existência constante de organismos inferiores não nos oferece dificuldade alguma. Na verdade, a Seleção Natural, ou sobrevivência do mais apto, não leva necessariamente a um desenvolvimento progressivo, apenas se apodera das variaçóes que se apresentam e que são úteis a cada indivíduo nas relaçôes complicadas de sua existência (Darwin, 1859, p.188-189).

É útil assinalar nesse ponto que Darwin (1859) não compreende evolução como um processo com um fim determinado e, assim, não entende que a mudança possa ser classificada através de categorias distintas, como no caso spenceriano, em que evolução leva à heterogeneidade com integração, e dis-
${ }^{9} \mathrm{~A}$ ideia de ordenaçấo em uma "escala evolutiva" está disseminada nos trabalhos de Spencer. O autor trabalha com inúmeros exemplos que, não estranhamente, colocam a sociedade inglesa no ápice desta jornada em direção à heterogeneidade integrada, ou "evoluçáo". Do homem civilizado, como sendo fisicamente e mentalmente mais desenvolvido que outros povos ditos "selvagens"; da pequena divisão do trabalho

\author{
(homogênea) dos "povos \\ primitivos" comparada ao \\ livre mercado (heterogêneo) \\ das naçôes européias; da \\ "música primitiva" com poucos \\ instrumentos aos concertos \\ de clássica; da pintura \\ bidimensional egípcia ao \\ perspectivismo dos pintores \\ modernos. Tudo era visto \\ por Spencer como evidências \\ de que a civilização inglesa \\ estava, em todos os sentidos, \\ à frente das outras culturas. \\ É interessante notar que
}

essas ideias spencerianas acerca de uma "hierarquia de culturas" são completamente refutadas pelo pensamento antropológico moderno; a título de exemplo, podemos citar que Lévi-Strauss, em $O$ pensamento selvagem (1962), assinala que os povos "primitivos" não possuem um pensamento "pré-científico", mas que, ao contrário, compartilham dos mesmos princípios classificatórios do cientista moderno, parte $\ldots \ldots \ldots \ldots$ integrante de sua "ciência do concreto".

${ }^{10}$ Nesse sentido, Leão (2001) destaca que "Darwin preteria o termo evolução em favor do termo descendência com modificação, pois não se sentia à vontade com a noção de progresso ou com a ideia de estruturas orgânicas "superiores" $e$ "inferiores", uma vez que cada organismo se adapta bem a seu meio ambiente como o homem ao seu" (Leão, 2001, p. 142). 


\footnotetext{
${ }^{11}$ Carneiro (1973, p. 91-92)

destaca ainda que o conceito de evolução darwiniana é necessariamente compreendido como irreversível, ou seja, um processo que se desenrola em uma série histórica de eventos. Em Spencer, pelo contrário, acaba-se aceitando a reversibilidade dos processos através de uma dissolução ou retrogradação para um sistema mais homogêneo e menos integrado.
}

solução leva à homogeneização sem integração. Como vimos, para Darwin, a mudança dada em um tempo cronológico e regida pelos princípios de variação, herança e seleção é o que define de maneira sintética o termo evolução. ${ }^{11}$

Vemos assim que a influência de Von Baer na concepção de evolução de Spencer é óbvia. Porém, tão ou mais importante que compreender como se conforma a "escala evolutiva" da perspectiva spenceriana, é entender qual é a visão do autor sobre o funcionamento dos mecanismos de mudança. Nesse sentido, temos de assinalar a importância do lamarckismo como parte fundamental do ferramental teórico utilizado por Spencer.

Foi a partir de Social Statics (1851) que Spencer começou a incorporar as duas mais famosas concepçóes lamarckianas em sua obra: o princípio do uso e desuso e o princípio de herança das características adquiridas. A perspectiva lamarckiana compreendia que os hábitos dos animais complexos (aqueles que possuem sistema nervoso) definem uma variável-chave que conecta as circunstâncias ambientais à mudança orgânica. Haines resume bem a cadeia causal qua a visão lamarckiana estabelece:

"Environmental changes create new needs, new needs require new habits, which, in turn, exercise organs differentially to produce changes in organic structures that can be inherited" (Haines, 1988, p. 1205).

Nesse sentido, uma decorrência importante do processo de mudança lamarckiano é que os hábitos dos organismos (função) alteram a sua forma (estrutura) e não o contrário. Outra característica relevante e implícita à teoria é que os organismos devem permanecer em harmonia com o seu meio. Assim, ambientes mutáveis exigem organismos mutáveis, mantendo de forma dinâmica uma suposta harmonia entre o organismo e o ambiente.

Spencer absorve completamente a ideia de mudança lamarckiana. Para o autor, a função tem primazia frente à estrutura e as duas avançam conjuntamente de modo a se equilibrar com o ambiente. Spencer (1851) afirma que os homens mudam fisicamente e mentalmente com o objetivo de se adaptar a distintos ambientes, sendo que isso explicaria a existência de diferentes raças. $\mathrm{O}$ autor é categórico:

That such changes are towards fitness for surrounding circumstances no one can question [...] This law of physical modification, is the law of mental modification also. The multitudinous differences of capacity and disposition that have in course of time grown up between the 
Indian, African, Mongolian and Caucasian races, and between the various subdivisions of them, must all be ascribed to the acquirement in each case of fitness for surrounding circumstances (Spencer,1851, p. 9-10)

De forma astuta, Spencer combinou a epigenética de Von Baer com os princípios lamarckianos: a primeira explicaria a direção da evolução, a segunda desvendaria os seus mecanismos. Com esse construto Spencer compreende que a mudança, como evolução, deve ir em direção a uma crescente heterogeneidade e possui um fim inevitável: o equilíbrio definitivo. Nesse sentido, Spencer elabora um conjunto de leis fenomênicas que se encaixam perfeitamente à sua lei fundamental da persistência da força que, como sua congênere das ciências físicas, possui o resultado lógico do equilíbrio. Revisando esses conceitos, La Vergata (1995) esclarece a ideia central da biologia de Spencer:

"The basic object of his biology is the study of the continuous interaction between the organism and its environment. Life is the maintenance of a moving equilibrium of forces acting in accordance with the ultimate laws of redistribution of matter and motion" (La Vergata, 1995, p. 149).

Para Spencer, portanto, a evolução é uma escalada através da qual os indiví- duos vão se adaptando às condições ambientais mutáveis, gerando uma maior heterogeneidade das estruturas, num processo dinâmico de constante desequilíbrio e reequilíbrio que possui como telos o equilíbrio final, chamado por Spencer, no caso da evolução da sociedade, de estado social. Em tal equilíbrio social os indivíduos não sofreriam mais alteraçóes, uma vez que as faculdades individuais seriam exatamente aquelas exigidas pelas circunstâncias, ou seja, alcançar-se-ia a perfeição. Hiskes (1983) entende que o equilíbrio seria o pote de ouro no fim do arco-íris da evolução spenceriana, ou, em outra perspectiva, "Spencer might as well speak of heaven" (Hiskes, 1983, p. 603). ${ }^{12}$ La Vergata assinala essa ideia de perfeição como telos da evolução: sobre "o desconhecido" (unknowable), vendo-se aí claramente como a ciência de Spencer náo entra em conflito com o pensamento teológico, como assinalado pelo seguinte trecho: "While the beliefs to which analytic science thus leads, are such as do not destroy the object-matter of religion, but simply transfigure it, science under its concrete forms enlarges the sphere for religious sentiment" (Spencer, 1862, p. 214). 
Progress is the gradual attainment of a balance between the faculties and the environment, the progressive disappearance of what is wanting in the development of faculties. In the ideal man, every faculty will be exactly commensurate with the demands of circumstance... Spencer's conception of social development is still firmly rooted in his conception of natural processes; in a continuous process of adaptation, the individual and society are destined to reach higher and higher states of equilibrium until they reach perfection. We have nature to thank for this. Spencer passionately avows his faith in the universal tendency of nature towards perfection (La Vergata, 1995, p.135).

Ao contrário da evoluçáo spenceriana, na teoria evolucionária darwiniana não existe espaço para a ideia de equilí- brio (Carneiro, 1973, p. 80). O equilíbrio e a perfeição são exigências teóricas das ciências fundadas em conceitos que Popper (1950) sintetizou como "essencialismo". ${ }^{13}$ Tal visão dominava o pensamento científico vitoriano, sendo Spencer um de seus representantes. O que Darwin (1859) fez, de forma pioneira e contrária à tradiçáo científica de seu tempo, foi dar atenção àquilo que o essencialismo procura ignorar: a variação do mundo sensível. ${ }^{14}$

Como vimos, para Darwin (1859) a variação era o combustível dos processos evolucionários. É a cumulatividade dessas mudanças, ocasionadas por um processo histórico dado em longos períodos de contínua Seleção Natural, que explica a complexidade da vida.

Em Spencer, a variação se dá pela ação dos princípios lamarckianos. Assim,
${ }^{13} \mathrm{O}$ termo foi cunhado por Popper (1950) na sua análise dos fundamentos filosóficos e metodológicos do pensamento tipológico platônico e aristotélico. De maneira sintética podemos dizer que tal perspectiva se funda na distinção entre o mundo sensivel e a essência, sua causa. Todos os fenômenos do mundo material e sensível seriam cópias imperfeitas de um estado perfeito essencial. O sensível seria ilusório e a essência real, sendo esta última o objeto a ser estudado pelo homem, alcançável apenas através da faculdade da razão. Essa perspectiva permeou o desenvolvimento das sociedades ocidentais, incluindo sua religião e ciência. Sober (1980, p. 35) destaca que a ideia de essência está presente em qualquer tabela periódica, em que o número atômico seria a essência da pureza do elemento químico.

De acordo com Mayr (1982),
a ideia da Física como um
caminho para entender
as essências alcançou “its
greatest triumph in Newton's
unification of terrestrial
and celestial mechanics" (Mayr,
1982, p.39). Para
uma visão mais completa
sobre as relaçôes entre a
economia e o pensamento
essencialista, indicamos Luz e
Fracalanza (2010).
14 Dennett (2006) enfatiza
a oposição entre a visão
darwiniana e os conceitos
essencialistas: "One of the central lessons of Darwinian thinking is that essentialism must be abandoned: the imagined "essence of life" has to be approached by one imaginable chain or another of simple agents or agencies stretching from the clearly nonliving to the clearly living, and only a lexicographical decision is going to "draw the line" (Dennett, 2006, p.107). 
o meio induz modificaçóes nos indivíduos, que se alteram de maneira ativa em resposta às mudanças de seu ambiente. $A$ transformação seria assim somente uma variável de ajuste e não a fonte da diversidade. Nesse sentido, apesar de Darwin (1859) não rechaçar a possibilidade de o meio induzir de forma ativa mudanças nos organismos, sua ênfase maior sempre recaiu sobre a ideia de Seleção Natural. ${ }^{15}$ Desta maneira Leakey (2007) assinala a importância da Seleção Natural para Darwin e para o pensamento evolucionário moderno:

\section{"Embora A origem das espécies tenha sido} alterada entre a primeira e a sétima edição, o principal objetivo de Darwin permaneceu constante: demonstrar a força da Seleção Natural na formação gradual das novas espécies. A ciência moderna tem demonstrado a validade da confi- ança de Darwin em suas descobertas"

(Leakey, 2007, p.26). ${ }^{16}$

A complexidade dos organismos biológicos é explicada por Darwin (1859) pela ação da Seleção Natural dada em longos períodos. A seleção de Darwin não leva necessariamente a um aumento da heterogeneidade e integração, mas apenas revela a adaptabilidade dos organismos ao meio (fitness). A seleção darwiniana tem um importante papel criativo: ela vagarosamente vai permitindo a emergência de novas estruturas dentro de um mundo altamente dinâmico e mutável, sendo que sua ação é o que explica a existência das estruturas mais simples e, ao mesmo tempo, das mais complexas.

Spencer também utiliza o termo Seleção Natural, porém, dentro de sua ideia de "evolução cósmica", ela possui

\begin{abstract}
${ }^{15}$ Em Darwin (1859), o autor apresenta sua dúvida acerca da possibilidade de o ambiente afetar diretamente as variações nos seres vivos.

"Não conseguimos determinar quanto deve ser atribuido à ação acumuladora da Seleção Natural e quanto às condiçóes de vida [...]

Os naturalistas poderiam citar diversos exemplos de espécies que se mantiveram
\end{abstract}
imutáveis, sem apresentar qualquer variação, mesmo vivendo sob condiçóes climáticas muito diversas. Consideraçōes como essas me fazem atribuir pouca importância à ação direta das condiçóes de vida" (Darwin, 1859, p.199). Sobre a importância que Darwin sempre atribuiu à Seleção Natural sobre a ação direta das condições de vida (the direct action of external

conditions) e mesmo sobre o papel dos efeitos herdados do uso e desuso das partes (the inherited effects of use and disuse of parts) nas diversas ediçóes de $A$ origem das espécies, consultar Freeman (1974).

${ }^{16}$ É importante assinalar que a biologia moderna rejeita completamente os princípios lamarckianos como explicaçáo para a mudança no mundo vivo. A variação aleatória dos genes dos estudos de Mendel e Weissmann foi responsável por eliminar a ideia de herança das características adquiridas das ciências biológicas. Hoje, o conhecido "dogma central da genética molecular" rechaça integralmente a visão lamarckiana, afirmando que "a informação caminha em uma única direção: do DNA para fora” (Leakey, 2007, p.31). 
mera função acessória. Em Spencer, os caminhos da mudança já estão dados, o lamarckismo é o mecanismo par excellence que dita o compasso das modificações dos indivíduos em relação ao seu ambiente, interrompendo sua função no momento em que o equilíbrio final for alcançado. A Seleção de Spencer possui um papel completamente avesso à Seleção Natural criativa de Darwin, sendo que sua função se restringe à eliminação dos organismos que não conseguiram reagir de forma adequada às exigências de seu ambiente. Para Spencer, a Seleção Natural é uma mera vassoura, que retira a impureza do mundo real, de sua perspectiva essencialista de progresso e equilíbrio.

De forma sintética e para maior clareza do argumento, agrupamos no
Quadro 1 os principais pontos que diferenciam o conceito de evolução spenceriana da perspectiva evolucionária darwiniana. Encontramos no quadro, de forma resumida, os elementos mobilizados por cada autor para fundamentar suas ideias específicas sobre a evolução.

Traçar os divisores teóricos e filosóficos que separam a "evolução" spenceriana da darwiniana é uma tarefa reveladora que aponta para a distância das concepções científicas desses dois importantes pensadores da intelectualidade vitoriana. Spencer deixou sua marca no pensamento moderno e sua visão acerca da evolução (como progresso) até hoje habita as mentes menos atentas à história do pensamento evolucionário. Darwin, por outro lado, realizou uma profunda revolução científica, sendo o responsável pela

\section{Quadro 1 - Darwin X Spencer, uma comparação sintética}

\begin{tabular}{|c|c|c|c|c|c|c|}
\hline & $\begin{array}{c}\text { Abrangência da } \\
\text { Teoria }\end{array}$ & $\begin{array}{l}\text { Paradigma } \\
\text { Científico }\end{array}$ & Evolução & Variação & Seleção Natural & $\begin{array}{l}\text { Ideia de } \\
\text { Progresso }\end{array}$ \\
\hline $\begin{array}{l}\text { Charles } \\
\text { Darwin }\end{array}$ & $\begin{array}{l}\text { Organismos } \\
\text { vivos }\end{array}$ & Biológico & Como processo & $\begin{array}{l}\text { Em aberto, } \\
\text { mutaçáo como } \\
\text { combustível da } \\
\text { mudança }\end{array}$ & Poder criativo & Ausente \\
\hline $\begin{array}{l}\text { Herbert } \\
\text { Spencer }\end{array}$ & $\begin{array}{l}\text { Universal, } \\
\text { ontologia } \\
\text { aplicada a todos } \\
\text { os sistemas }\end{array}$ & Físico & $\begin{array}{l}\text { Como Fim } \\
\text { (teleologia) }\end{array}$ & Lamarckismo & $\begin{array}{l}\text { Vassoura natural, } \\
\text { eliminaçáo do } \\
\text { imperfeito }\end{array}$ & $\begin{array}{c}\text { Fundamental, } \\
\text { adoção dos } \\
\text { conceitos de von } \\
\text { Baer }\end{array}$ \\
\hline
\end{tabular}

Fonte: elaboração própria. 
elaboração das bases de todo o pensamento evolucionário a partir de então.

Esse trabalho de demarcação teórica acerca das interpretaçôes que Darwin e Spencer constroem sobre os processos evolucionários nos fornece elementos indispensáveis para a análise da formação (ou formaçóes) do próprio pensamento evolucionário dentro das ciências econômicas. Nesse sentido, e como mera incursão inicial, procurar-se-á tecer aqui breves consideraçóes acerca da influência de Darwin e Spencer sobre o pensamento de Alfred Marshall, buscando apresentar, de maneira sintética, o alcance da interpretação evolucionária de suas ideias, focando fundamentalmente em alguns aspectos da construção teórica que o autor realiza nos Principles (1890).

\section{3_A "Evolução" de Alfred Marshall}

Uma característica marcante do atual estágio das ciências econômicas é o crescente interesse sobre a utilização de conceitos evolucionários em suas formulações teóricas. Se tal fenômeno possui raízes no Institucionalismo Original de Thorstein Veblen ${ }^{17}$ vemos, porém, que o termo "economia evolucionária” se difundiu especialmente após a publicação de Uma teoria evolucionária da mudança econômica, de Nelson e Winter (1982). Com efeito, o impacto de tal trabalho foi extrema- mente marcante, bastando observar que, na história das ideias econômicas, nunca o termo

\section{"Evolução" e suas derivaçôes etimológi- cas foram tão utilizados em publica- çôes acadêmicas como ocorreu a partir da década de 1980 (Hodgson, 2001, p. 25). ${ }^{18}$}

Além de promover um profícuo debate sobre a reconstrução dos fundamentos filosóficos e metodológicos da economia, a possibilidade aberta pela abordagem evolucionária também gera um movimento de suma importância para uma possível reinterpretação de certos momentos da história do pensamento econômico. Tal movimento consiste em procurar resgatar, dentro da própria história das ideias econômicas, a contribuição de certas escolas e autores para a conformação do pensamento evolucionário contemporâneo. Para além de uma questão de justiça histórica, a busca do pioneirismo das ideias em economia evolucionária é importante, uma vez que a discussão atual sobre os fundamentos dessa abordagem específica pode enriquecer-se enormemente dos estudos provenientes desse resgate histórico.

Fundada no código de ciência darwiniano, essa revisão evolucionária da história do pensamento econômico gera ricos debates e possibilidades de desenvolvimentos futuros. Um exemplo atual
${ }^{17}$ Ver principalmente

Veblen (1898).

${ }^{18}$ Hodgson (2001, p. 25) apresenta um gráfico em que podemos observar a proliferação do uso do termo "evolução" nas publicações acadêmicas a partir década de 1980 , comparado ao seu uso menos disseminado em décadas anteriores. Vale ressaltar que essa popularização evolucionária gerou uma publicaçáo específica dedicada ao tema, o Journal of Evolutionary

Economics, que iniciou seus trabalhos em 1991. 
é o interesse renovado pelo pensamento dos Institucionalistas Originais, ou até mesmo a busca por uma reinterpretação do conteúdo evolucionário dos autores da tradição schumpeteriana. Assim, esse tipo de estudo criou meios para possíveis integraçóes teóricas de escolas que, até então, pareciam possuir perspectivas substancialmente diferentes. ${ }^{19}$

No bojo desse processo, Alfred Marshall aparece como figura de destaque dessa proposta de revisão da perspectiva evolucionária dentro da história do pensamento econômico. $\mathrm{O}$ autor ocupa, no debate, um papel importante e talvez único, tendo em vista a inegável influência de seu construto teórico tanto para a economia neoclássica quanto para o desenvolvimento de uma heterodoxia evolucionária. Dessa maneira, a célebre frase de Pigou, "it's all in Marshall", possui nesse esforço revisionista um caráter emblemático. ${ }^{20}$

Porém, segundo cremos, a compreensão de Marshall como autor evo- lucionário é problemática, visto que os fundamentos teóricos de uma concepção neoclássica de indivíduos e firmas é totalmente incompatível com a perspectiva populacional do pensamento evolucionário darwiniano. Ou seja, se Marshall tentou agrupar os códigos de ciência newtoniano e darwiniano sob o mesmo construto teórico, uma das duas perspectivas teve de ser sacrificada para que a outra pudesse prevalecer.

De fato, a controvérsia acerca do caráter evolucionário do pensamento marshalliano é grande, gerando opiniōes diametralmente opostas a respeito da natureza de sua contribuição teórica à economia. Glassburner (1955), por exemplo, ressalta que Marshall é um legítimo representante do utilitarismo inglês e um equilibrista típico de seu tempo, afastado por completo da ideia darwiniana de evolução:

Alfred Marshall's work is commonly classified as "micro-statics" in modern termi-
${ }^{19} \mathrm{O}$ Nesse escopo assinalamos as recentes tentativas de associação teórica entre a perspectiva institucionalista de Thorstein Veblen e a "resource based perspective" dos neoschumpeterianos, em que se busca uma abordagem que compreenda instituiçóes e rotinas de maneira integrada.

\section{Para uma visão mais} aprofundada sobre o assunto, indicamos Foss (1996), Winter (1990) e Nelson (1995).

${ }^{20}$ Foa (1982) assinala esse caráter paradoxal da contribuição de Marshall para a economia: "Paradoxically, the one major economist who was deeply influenced by

biological darwinism
was the same Alfred Marshall
who (with Léon Walras)
was the co-founder of
the mutual dependence
equilibrium school of
economics" (Foa, 1982,
p.114). De maneira sintética,
seguindo Alvey (1987) e
Keynes (1924), podemos

biological darwinism who (with Léon Walras) was the co-founder of the mutual dependence equilibrium school of economics" (Foa, 1982, p.114). De maneira sinté
seguindo Alvey (1987) e Keynes (1924), podemos

\author{
enumerar, entre outros \\ conceitos, as seguintes \\ contribuiçôes de Marshall \\ à teoria econômica: a ideia \\ da firma representativa, \\ do excedente do consumidor, \\ do tratamento do monopólio, \\ da elasticidade ( $\mathrm{da}$ \\ demanda), das economias \\ externas e internas.
}


nology. He is best known as the synthesist of several strains in the nineteenth century thinking, particularly in the fields of cost utility theory... In all of his writing, Marshall dealt with the individual, or with small units, and he dealt with them, for the most part, in terms of equilibrium positions, rather than in terms of process (Glassburner, 1955, p.577)

De outra parte, existem investigadores que apontam que Marshall pode ser visto como um dos pioneiros da abordagem evolucionária dentro das ciências econômicas. Foss (1991) é explícito nessa interpretação:

“A perhaps better understanding of Marshall's intentions may be obtained by interpreting him as a genuinely evolutionary theorist" (Foss, 1991, p.67).

Assim, Marshall poderia ser considerado, de forma um pouco mais restrita, "a patron saint for the new evolutionary economics - at least in the context of the theory of the firm" (Foss, 1991, p.71).

Nesse contexto, uma inevitável pergunta emerge: quais são os elementos mobilizados pelo pensamento marshalliano que permitem que ele seja interpretado como um dos fundadores de dois campos de estudo em economia tão distantes e que não possuem fundamentos teóricos comuns? Cientes da inquestionável contribuição do autor à teorização neoclássica, duas explicaçóes poderiam dar solução a essa controvérsia: a primeira seria a de que Marshall possui uma obra contraditória, em que encontramos um forte e constante atrito entre uma perspectiva ligada à doutrina das essências e aos conceitos evolucionários; a segunda explicação, e que iremos defender aqui, é a de que a perspectiva evolucionária de Marshall não é contraditória com relação aos fundamentos metodológicos e filosóficos da economia neoclássica, pois ela não compreende a ideia darwiniana de ciência evolucionária, mas sim se associa muito mais a outra construção popular da ciência vitoriana, ou seja, a concepção spenceriana de "Evolução". ${ }^{21}$

Num primeiro momento, somos tentados a afirmar que a interpretação sobre o caráter spenceriano do pensamento "evolucionário" de Marshall possui o aval das evidências coletadas nos seus próprios trabalhos e nos relatos biográficos sobre o economista. No prefácio da primeira edição dos Principles, Marshall dá crédito à influência de Spencer e Hegel sobre sua obra: "Estas duas classes de influência afetaram, mais do que qualquer outra, a essência das opinióes manifestadas no presente tratado" (Marshall, 1890, p. 6). Keynes (1924), citando as descrições dadas pela Sra. Marshall, assina-
${ }^{21}$ É importante ressaltar que não existe consenso acerca da interpretaçáo spenceriana da ideia de "Evolução" de Marshall. Apoiamos-nos aqui nos trabalhos de Parsons (1932), Moss (1982, 1990), Foa (1982), Hodgson (1993), Guillebaud (1942), Fishburn (2004), Aspers (1999), Staveley e Alvey (1988) e Yamamoto (2008), todos apontando para a grande influência de Spencer sobre a obra de Marshall. Porém, contrariando a linha argumentativa seguida por esses autores, encontramos em Foss (1991, 1994), Hammond (1991) e Loasby $(1986,1990)$ a defesa de que Marshall segue um código de ciência evolucionário estritamente darwiniano. 
la que o economista costumeiramente lia Spencer em suas temporadas nos Alpes:

"He would walk with knapsack on his back for two or three hours. He would sit down, sometimes on a glacier, and have a long pull at some book-Goethe or Hegel or Kant or Herbert Spencer - and then walk on to his next haltingplace for the night" (Keynes, 1924, p.323). Groenewegen (1995)

também nos dá evidências de que Marshall tinha profundo interesse pelos trabalhos de Spencer:

"Mary Paley Marshall also recalled he lectured her on Spencer's Social Statics and First Principles. Marshall's library contained all of Spencer's major works, including those published in the 1880 and 1890s" (Groenewegen, 1995, p. 167). Aspers (1999)

é categórico:

"Spencer was probably the sociologist that Marshall knew best, and he had all Spencer's books and kept them at his library where they were bound with a special cover" (Aspers, 1999, p. 654).

Porém, é importante assinalar que entender que a perspectiva evolucionária de Marshall possui certas influências spencerianas não significa dizer que o autor construiu um discurso evolucionário reflexo ao de Herbert Spencer, nem nos permite afirmar que a contribuição de Marshall não possui nenhuma validez como teoria evolucionária fundada nos princípios darwinianos. A bem da verdade, buscar compreender as possíveis repercussóes de Spencer sobre Marshall tem como objetivo apenas mostrar como o próprio pensamento marshalliano, assim como o spenceriano, foi fruto das ideias de uma época específica, sendo que a compreensão dos fundamentos dessas ideias pode contribuir para a reflexão a respeito dos muitos caminhos que a economia trilhou até os dias de hoje, incluindo aí a própria ideia contemporânea de economia evolucionária.

Dessa forma, devido à restrição de espaço inerente ao formato desse trabalho, assim como em razão da grande variedade de contribuiçóes à teoria econômica levantadas pela obra de Marshall, iremos nos restringir a um corte específico sobre a análise evolucionária do pensamento marshalliano. Realizaremos nossa investigação de duas maneiras distintas, porém claramente complementares. Em primeiro lugar, procuraremos mostrar que Marshall entende, assim como Spencer, a ligação teórica unidirecional entre a física e a biologia, sendo a segunda apenas um reflexo (ou uma lei fenomênica) derivado da primeira. Cremos que is- 
so nos capacitará a interpretar o papel que os princípios da continuidade e substituição desempenham dentro de sua ideia de Progresso. Em segundo lugar, num recorte mais específico, e propondo uma contribuição original ao debate, buscaremos evidenciar como a visão de firma representativa construída em Marshall (1890) atende aos requisitos fundamentais da concepção evolutiva de Spencer e se afasta dos conceitos evolucionários darwinianos.

\section{1_Marshall, Spencer e o "Progresso"}

É sabido que, apesar de ter provido todos os elementos para a construção da teoria do equilíbrio parcial, Marshall também era um recorrente crítico do raciocínio estático na economia. Hodgson (1993) assinala que foi a ideia de retornos crescentes e de irreversibilidade dos processos dados em um tempo cronológico que primeiramente mostrou a Marshall os limites da estática na economia:

"In particular, in his investigations of increasing returns, it became clear to him that a movement up or down the long-period supply curve is irreversible" (Hodgson, 1993, p. 58). ${ }^{22}$

Nesse sentido, Marshall assinalava com frequência a insuficiência teórica das analogias físicas para compreender o mundo econômico. Dessa forma, os traba- lhos do autor destacavam recorrentemente a necessidade de que a economia estivesse mais aberta às ideias provenientes dos estudos do campo biológico. $\mathrm{Na}$ sua aula inaugural como professor em Cambridge, Marshall destacou o século XIX como palco de mudanças significativas, no qual o paradigma científico físico-matemático poderia dividir espaço com uma perspectiva orgânica que então emergia:

"At the beggining of the nineteenth century the mathematico-phisical group of sciences as in the ascendant [...] As the century wore on, the biological group of sciences were slowly making way, and the people were getting clear ideas as to the nature of organic growth" (Marshall,1885, p. 154). ${ }^{23}$

Marshall entendia que a teoria econômica deveria se utilizar, com as devidas ressalvas, do rico repertório de analogias provenientes dessa mudança do pensamento científico, ou seja, recorrer às analogias biológicas para compreender processos complexos da economia:

There is a fairly close analogy between the earlier stages of economic reasoning and the devices of physical statics. But is there an equally serviceable analogy between the later stages of economic reasoning and the methods of physical statics? I think not. I think that in the later stages of economics better analogies are
${ }^{22}$ A consideração extensa da ideia de retornos crescentes de escala, que ocupa parte importante de sua obra, é responsável pelo célebre dilema de Marshall. Para uma discussão do referido dilema e de seus desdobramentos, ver Screpanti e Zamagni (2005).

${ }^{23}$ Esse mesmo trecho aparece no apêndice B dos Principles (1890, p. 341). 
to be got from biology than for physics; and consequently, that economic reasoning should start on methods analogous to those of physical statics, and should gradually become more biological in tone (Marshall, 1885, p. 314).

Nesse mesmo sentido, a partir do prefácio da quinta edição dos Principles encontramos a famosa asserção marshalliana de que "A Meca do economista está antes na Biologia econômica do que na Dinâmica econômica" (Marshall, 1890, p. 10).

Marshall (1890), na primeira edição dos Principles, já prometia um volume que lidaria com a dinâmica e o elemento tempo, um trabalho que seria basicamente inspirado nos desenvolvimentos das ciências biológicas. Porém, tal volume nunca foi escrito. Keynes (1924) e Whitaker (1990) creditam isso a um excessivo per- feccionismo e "medo de falhar" que o autor possuía, ${ }^{24}$ associado às diferentes atividades nas quais ele se envolveu depois da publicação dos Principles. ${ }^{25}$

Porém, ao analisar as próprias explicaçóes que Marshall (1890) nos dá a partir do prefácio da sétima edição dos Principles, encontramos que o autor entende que a sua ideia de economia dinâmica já está contida fundamentalmente no livro sexto, intitulado

"A distribuição da Renda Nacional", no qual as "novas forças são libertadas do sono hipotético que lhes foi imposto [...] Gradualmente a área do problema dinâmico se torna maior, diminui a área abrangida por pressuposiçôes estáticas provisórias” (Marshall, 1890, p.11). ${ }^{26}$

Assim, apesar de Marshall nunca ter escrito o seu "volume evolucionário"
${ }^{24}$ As constantes revisóes do que era ainda o volume I dos Principles é o motivo mais enfatizado por Keynes (1924) para a não publicação do volume II: "He also spent much time on the successive revisions of the Principles, the most important changes being introduced in the third edition, published in 1895, and the fifth edition in 1907[...] These revisions were a great obstacle to his getting on with what was originally intended to be Volume II of the Principles" (Keynes, 1924, p.360).

${ }^{25}$ Dentre as atividades, destacam-se o seu papel ativo na Royal Commission on Labour (1891-1894), a apresentação de memorandos para o Indian Currency Comitee (1899) e o Royal Comission on Local Taxation (1899), além da fundaçáo da British Economic Association (1890). Whitaker (1990) analisa que, de 1890 a 1903 ,

Marshall estava trabalhando ativamente no volume II

dos Principles. Porém, em 1907, "He abandon all hope of completing his Principles on the original plan, a decision reached by 1907 and finalized in 1910, when 'Volume I' was removed from the title page" (Whitaker, 1990, p.194).

${ }^{26}$ Vale assinalar que a

"dinâmica”, para Marshall (1890), busca diminuir a proeminência do coeteris paribus de sua análise estática, permitindo a "liberação de novas forças". Esse seria um sinal do "progresso" da disciplina. Hammond (1991) aponta que, para Marshall, "in the latter stages of the discipline's development, economics neared its "mecca", our knowledge would be such that the coeteris paribus pound would no longer be used" (Hammond, 1991, p.98). 
dos Principles, podemos, a partir da análise dos fundamentos teóricos da parte publicada dessa obra específica, entender qual é a ideia de "Evolução" que o autor absorve para seu trabalho, tendo em vista as diferentes construções sobre a mudança evolucionária geradas na era vitoriana.

De maneira geral, podemos dizer que Marshall utiliza-se de dois princípios fundamentais para entender a evolução dos processos econômicos: o princípio da continuidade e o princípio da substituição.

Talvez a epígrafe "natura non facit saltum", destaque da página de abertura dos Principles, cristalize de forma mais clara a agência do princípio da continuidade em Marshall (1890). Através desse princípio, o economista assinala que a mudança deve ser vista como um processo incremental em que as variaçóes não possuem caráter disruptivo, mas sim são levadas a cabo gradualmente. Moss (1982) assinala que é o princípio da continuidade que faz com que a ideia de desenvolvimento econômico de Marshall seja completamente oposta à de Schumpeter, que absorve a concepção de mudança disruptiva. Para Moss, a continuidade é central para entender a perspectiva orgânica de Marshall:

\section{"What was most important to Marshall was the notion of "continuous change - that economic development, like na- ture itself, changes in small increments" (Moss, 1982, p. 2).}

É nessa visão de continuidade que vemos um importante paralelismo entre o ideal de evolução spenceriano e a abordagem marshalliana. ${ }^{27}$ Como vimos, a evolução para Spencer é linear e sem rupturas, uma progressão na qual função e estrutura vão gradualmente e mutuamente se modificando e gerando estruturas cada vez mais heterogêneas e integradas. O lamarckismo é o elemento central dessa interpretação dos processos de mudança, sendo que o gradualismo é resultado tão somente da

$\begin{array}{lll}{ }^{27} \text { É importante apontar que } & \text { tipológica de ordenação } & \text { que Marshall (1890) utiliza } \\ \text { o moto "natura non facit } & \text { da natureza, divinamente } & \text { a expressão com motivos } \\ \text { saltum" vem sendo usado } & \text { fixada. Assim, ao contrário } & \text { distintos dos de Darwin: } \\ \text { desde Linnaeus no contexto } & \text { da interpretação spenceriana } & \text { "Whatever his reasons for using } \\ \text { do pensamento evolucionário. } & \text { (e marshalliana) acerca da } & \text { it, [...] the justification which } \\ \text { O termo também foi } & \text { expressão, Darwin não estava } & \text { he subsequently offered was } \\ \text { utilizado por Darwin } & \text { se referindo a um processo de } & \text { thoroughly un-Darwinian in } \\ \text { (1859) para contrastar sua } & \text { progressão linear. Fishburn } & \text { nature” (Fishburn, 2004, p. 61). }\end{array}$


absorção dos princípios lamarckianos pela concepção de "Evoluçáo" de Spencer. ${ }^{28}$

Assim, a ideia de crescimento orgânico ou "Evolução" de Marshall (1890) é construída sobre um princípio que desempenha um papel análogo ao resultado do componente lamarckiano da "Evolução" de Spencer, ou seja, um gradualismo progressista.

Apesar do princípio da continuidade explicar que a mudança ocorre de maneira gradual, ele não revela os mecanismos que fazem com que a mudança ocorra. Para isso Marshall (1890) utiliza o princípio da substituição. Tal princípio é o componente fundamental da decisão racional, que dirige a ação humana entre diferentes alternativas para que o resultado seja maximizado, sendo o cálculo diferencial a sua ferramenta analítica. Para Marshall, esse princípio não era aplicável somente aos negócios, mas sim à vida como um todo, sendo que a ideia de utilidade marginal é uma parte integrante desse princípio (Aspers, 1999, p. 654). Moss
(1982) assinala que, para Marshall, o princípio de substituição manifesta-se em diferentes escalas (firmas e mercados):

The same way individual businessman substitutes one technique for another, the market substitutes one businessman for another! Some firms succeed while others do not, and the less efficient are weeded out by the selection process of the market. Thus, the principle of substitution operates both within firms and between firms (Moss, 1982, p.4)

O princípio de substituição nos revela uma característica fundamental que torna a abordagem orgânica marshalliana compatível com a ideia de evolução construída por Spencer: a fundamentação física dos processos de mudança. Ao entender que o cálculo na margem é o mecanismo responsável pela mudança, Marshall (1890) se associa a Spencer no sentido de entender que a evolução decorre da ação de mecanismos dados pelas ciências físicas, pois, assim como para Spencer,
${ }^{28}$ Uma grande quantidade de autores destaca Marshall como um explícito defensor do lamarckismo. Um exemplo claro pode ser retirado da relação entre ambiente e desenvolvimento das "raças" que Marshall (1890) apresenta no Apêndice A: "O clima que tornou possível a civilização primitiva condenou-a à fraqueza. Nos climas mais frios a natureza fornece uma atmosfera vigorizante" (Marshall, 1890, p. 308). Nesse sentido, o autor cita os estudos de Francis Galton para dizer que os ingleses, como "raça" dirigente na Índia, “poderá manter perfeitamente a sua constituição vigorosa, por muitas geraçóes, mediante o emprego amplo do gelo artificial, ou dos efeitos refrigerantes do ar condicionado" (Marshall, 1890, p.308-309). Para uma análise mais apurada a respeito das influências do lamarckismo em Marshall recomendamos, especialmente, Moss (1990, 1982). 
"Physical nature for Marshall is not confined to the inanimate world of matter investigated by physics and chemestry" (Staveley e Alvey, 1988, p. 374).

Dessa forma, apesar de se utilizar de analogias biológicas, Marshall (1890) pôde reter a análise de equilíbrio mecânico. Assim, Alvey (1987) enfatiza que "Marshall was not a 'revolutionary' but was engaged, in Kuhninan language, in normal science" (Alvey, 1987, p. 15). É interessante, nesse sentido, entender que é essa subordinação do pensamento biológico às ciências físicas, típica da abordagem spenceriana, que permite que Marshall utilize, de maneira não contraditória, um ferramental derivado da mecânica newtoniana em conjunto com sua ideia biológica. ${ }^{29}$ Segundo Thomas (1991), Marshall não conseguiu escrever o "volume dinâmico" de Principles por um lado por que, no final do século XIX, o pensamento spenceriano vinha sofrendo fortes críticas, ${ }^{30} \mathrm{e}$ por outro devido à incompatibilidade da ideia de evolução de Marshall em relação ao pensamento darwiniano em ascendência (já bem sedimentado com os desenvolvimentos da genética mendeliana):

\section{"He has come to realize more and more that the study of organic growth neces- sitated a break with his neoclassical system as definite as the break which he had made with the Ricardo-Mill system." (Thomas, 1991, p. 11).}

Além de fornecerem as bases pelas quais a dinâmica marshalliana se desenrola, os princípios de continuidade e substituição fundamentam o que talvez seja a mais forte repercussão da ideia de "Evolução" de Spencer sobre Marshall, a saber, a concepção de Progresso. Assim como Spencer, Marshall entende Progresso como sinônimo de "Evolução", ou seja, uma posição relativa caracterizada por um aumento da heterogeneidade e inte-

\footnotetext{
${ }^{29}$ Hodgson (1993) assinala que foi a física por trás da abordagem biológica de Marshall (1890) que permitiu a seus seguidores neoclássicos (Pigou, Robbins, Robinson e Chamberlin) substituírem com relativa facilidade os elementos biológicos de seu

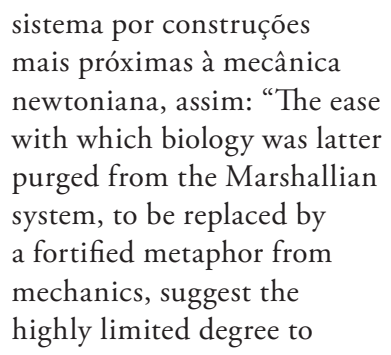
purged from the Marshallian system, to be replaced by a fortified metaphor from mechanics, suggest the highly limited degree to

which distinctively biological ideas had been originally implanted by Marshall in his Principles" (Hodgson, 1993, p.64).

${ }^{30}$ É importante assinalar nesse sentido que, três anos depois da primeira edição dos Principles, o biólogo alemão August Weissmann publicou um popular ensaio na Contemporary Review, no qual corrigia os erros de Spencer com relação à biologia moderna e sepultava a teoria da herança de características adquiridas de Lamarck (Moss, 1990, p. 184). 
gração. ${ }^{31}$ Nesse sentido, Moss (1990) sintetiza a posição de Marshall: "In short, biology meant for Marshall, the scientific study of progress". (Moss, 1990, p.182).

Com efeito, o capítulo VIII do Livro IV dos Principles nos dá todos os elementos para verificar como Marshall (1890) absorve a ideia de Progresso de Spencer para entender a mudança econômica:

$O$ desenvolvimento de um organismo, wseja físico ou social, envolve uma crescente subdivisão de funçóes das suas diferentes partes, ao mesmo tempo que aumenta a conexão intima entre elas. Essa crescente subdivisão de funçóes, ou diferenciação, como é chamada, manifestase com respeito à indústria sob diversas formas, tais como a divisão do trabalho $e$ o desenvolvimento da especialização da mão de obra, do conhecimento e da maquinaria, ao passo que a integração, ou seja, o aumento das relaçóes e a firmeza das conexóes entre as diferentes partes de um organismo industrial se manifesta no aumento da estabilidade do crédito comercial, nos meios e hábitos de comunicação por terra e por mar, por estrada de ferro e por telégrafo, correio e imprensa" (Marshall, 1890, p. 212).
Marshall (1890) entende que a divisão do trabalho na indústria pode ser tomada como uma medida do Progresso, já que um "aperfeiçoamento da maquinaria e um aumento do volume da produção causam uma subdivisão minuciosa do trabalho" (Marshall, 1890, p.225). O autor compreende que a heterogeneidade é uma característica marcante da organização "evoluída" do mundo industrial. Nos moldes de Spencer, Marshall (1890), em seu Apêndice A, estende essa ideia de Progresso através da divisão do trabalho para analisar diferentes civilizações. Marshall vê a hegemonia comercial e industrial inglesa como uma mera extensão de um processo de adaptação de meios a fins que tomou lugar conforme a sociedade progredia de um estado mais primitivo até culminar na revolução industrial:

Mesmo nos paises mais subdesenvolvidos encontramos indústrias muito especializadas mas não encontramos em cada uma delas o trabalho tão dividido de maneira que o planejamento e a organização do negócio, sua direção $e$ os seus riscos, estejam a cargo de um grupo de pessoas, enquanto o trabalho
${ }^{31}$ Em Marshall (1898) o autor é explícito em entender "Progresso" como sinônimo de "Evolução" e de "crescimento orgânico": "Progress or

\section{evolution, industrial and social,} is not mere increase and decrease. It is organic growth, chastened and confined and occasionally reversed by the decay of innumerable factor, each of which influences and is influenced by those around it" (Marshall, 1898, p.317). Não podemos nos esquecer, como Keynes (1924) ressalta, que o "volume dinâmico" dos Principles iria ser nomeado de "Progress: Its Economics Conditions". 
manual necessário seja feito por mão de obra contratada. Essa forma de divisão do trabalho é caracteristica, geralmente, do mundo moderno, e em particular da raça inglesa. Pode ser uma fase meramente passageira do progresso humano, superada pelo desenvolvimento ulterior da livre empresa que a trouxe à existência (Marshall,, 1890, p. 325). ${ }^{32}$

A ideia de Progresso aparece em inúmeras passagens dos Principles, sendo utilizada para se referir a fenômenos substancialmente diferentes. A partir desse fato, e procurando centrar nossa análise nos aspectos metodológicos da perspectiva "evolucionária" marshalliana, entende-se aqui que uma maneira sintética e profícua de verificar como Marshall (1890) mobiliza os princípios de continuidade e substituição para fundamentar sua ideia de "Evolução" pode ser levada a cabo restringindo nosso escopo à compreensão dos conceitos dinâmicos que inter- relacionam firma e indústria dentro de seu construto teórico.

\section{2_As "Firmas Marshallianas" e a "Evolução"}

A concepção de firma representativa, uma das contribuiçóes mais importantes dos Principles à teoria econômica, pode ser entendida como uma evidência da associação de uma visão de "Evolução" com a ideia equilíbrio. Como vimos anteriormente, Spencer entendia que o Progresso se movia em bases dadas por um constante desequilíbrio e reequilíbrio entre ambiente, estrutura e função, levado a cabo através dos mecanismos lamarckianos. Nesse sentido, buscaremos entender aqui como a ideia de firma representativa em Marshall não se opóe a nenhum dos elementos teóricos dessa concepção spenceriana, assumindo assim um visão em que evolução e equilíbrio se associam.
32 Para Marshall (1890),

Progresso não se restringe aos aspectos econômicos

da sociedade, mas também se estende a aspectos morais e à própria racionalidade dos indivíduos dessa sociedade. Seguindo os passos de Spencer, Marshall entende que a

\author{
racionalidade econômica \\ é um dos resultados da \\ "Evolução" e que as antigas \\ tradiçôes seriam eliminadas \\ pelas forças inerentes ao \\ Progresso. Para Marshall, a \\ industrialização era um \\ desenvolvimento inevitável \\ advindo do aumento da \\ racionalidade econômica.
}

\author{
Staveley e Alvey (1988) \\ sintetizam bem essa visão \\ específica do Progresso em \\ Marshall: "If rational choice \\ is morally good, economic \\ activity, being rational \\ choice, is also morally good \\ [...] Free competition by \\ forcing men to be both \\ self-reliant and deliberate
}

produce morally praiseworthy results such as trustworthiness, unselfishness and honesty" (Staveley e Alvey, 1988, p.380). Nesse sentido, Reisman (1987) assinala: "Marshall's economics not only grow, but, more significantly, also grow better" (Reisman, 1987, p.67). 
${ }_{33}$ É importante ressaltar que é esta interpretação acerca da firma marshalliana que fundamenta as ideias de alguns autores que defendem que Marshall pode ser considerado um seguidor do código darwiniano de ciência evolucionária (ver nota 20).
Marshall (1890) aborda a firma de duas maneiras distintas que, do ponto de vista de uma teoria darwiniana, são profundamente contraditórias. Nesse sentido, podemos dizer que Marshall nos apresenta ao mesmo tempo uma perspectiva populacional das firmas e outra visão significativamente tipológica.

A perspectiva populacional se funda no fato de que Marshall (1890) entende o caráter heterogêneo das firmas, assim como a grande variedade de açóes que o empresário que a comanda pode tomar. Nessa concepção de indústria de Marshall, são conspícuas as variações entre as empresas com respeito à alocação de competência empreendedora, estrutura de custos e desempenho inovativo. No capítulo VII do Livro VI sugere-se que nem os empresários, nem os negócios que eles administram são homogêneos. Marshall argumenta que a ação de cada homem de negócios é influenciada por oportunidades especiais, recursos, temperamento e associaçóes, sendo que essas características são únicas para cada indivíduo. A partir disso Marshall (1890) afirma:

"A esse respeito podemos dividir os empregadores e demais empresários em duas classes, os que inauguram novos e melhores métodos de negócio e os que seguem trilhas batidas" (Marshall, 1890, p. 216). Loasby (1986, p. 406) destaca ainda que, para Marshall, a liberdade econômica é o campo no qual o homem de negócios irá experimentar, com risco, algum novo método ou combinação de métodos que sejam mais eficientes que os anteriores.

Esse aspecto sobre a dinâmica das firmas, que chamamos de perspectiva populacional, não reserva espaço para a ideia de firma em equilíbrio. Nesse sentido, apesar de Marshall (1890) entender que no longo prazo a oferta da indústria permanece em equilíbrio com a demanda, as firmas que compóem essa indústria não estariam em equilíbrio:

"Long run industry equilibrium is a matter of equality between aggregate market demand and supply only. There is simply no pretension that individual firms are in equilibrium" (Foss, 1991, p. 67). ${ }^{33}$

A conhecida analogia marshalliana do capítulo XIII do Livro IV, em que o autor enxerga a "indústria como uma floresta e as firmas como árvores" (Marshall, 1890, p.226), assimila bem a relação que Marshall (1890) traça entre a variabilidade das firmas, incluindo aí a ideia de ciclo de vida, e o equilíbrio no nível da indústria. Porém, apesar de sua analogia biológica dar a clara impressão de que Marshall está a tratar de um processo substancialmente darwiniano, no qual variaçóes são 
selecionadas e retidas, pode-se argumentar, por outro lado, que Marshall não estava se referindo à variação e à seleção como componentes criativos dentro de um sistema populacional complexo, tendo em vista a construção teórica que o autor desenvolve em seguida, curiosamente nesse mesmo capítulo: a firma representativa.

Definida como "essa espécie particular de firma média, para a qual precisamos nos voltar a fim de ver até que ponto as economias internas e externas da produção em massa se têm expandido geralmente na indústria e no país em questão" (Marshall, 1890, p. 267), a firma representativa não é uma firma específica da indústria, nem uma firma típica, é uma firma imaginária que exibe, no microcosmo, as características representativas de toda a indústria. Segundo Hodgson:

"Not only is the substance of the representative firm inorganic, its application is mechanical. It is a reductive method of depicting a long-period equilibrium for the industry as a whole, by means of a theory of the firm" (Hodgson, 1993, p. 59).

A firma representativa, como construção teórica da análise do equilíbrio parcial, desfaz toda a possibilidade de interpretação darwiniana sobre a perspectiva evolucionária de Marshall (1890). ${ }^{34}$ Sua construção apaga a ideia de firma dentro de um conceito populacional, adequando-a a uma concepçáo profundamente tipológica. A firma representativa é uma ideia essencialista de firma, que apaga a variação como combustível da mudança e acaba por empossar o cálculo diferencial como ferramental analítico. Thomas (1991) mostra a incompatibilidade desse conceito de firma com o pensamento darwiniano:

\section{"If the "representative firm" is a biologi- cal concept, is it not strange that two- thirds of the references of it in the Prin- ciples are in Book V which is devoted to mechanical equilibrium analysis?" (Thomas, 1991, p.7).}

Porém, se a firma representativa faz com que Marshall (1890) se afaste do pensamento darwiniano, permite, ao mesmo tempo, que o economista se aproxime dos conceitos spencerianos da evolução. Os princípios de continuidade e substituição levando ao equilíbrio são facilmente aplicáveis para compreender a mudança na firma representativa. Nesse aspecto, a ação do empresário é entendida pela substituição na margem onde, ao longo de uma função de produção contínua, procura-se a combinação de fatores que resulte no maior lucro. Assim, na concepção essencialista de firma, a mudança advém do cálculo marginal que, nu-

\footnotetext{
${ }^{34}$ Foss (1991) diz que a concepção de firma representativa foi responsável por uma posterior supressão do pensamento evolucionário na economia, a partir de Pigou (1928), com a transformação da firma representativa para firma em equilíbrio. Assim: "The representative firm was the analytical device that Marshall employed to handle complexity. And to a very large extend it is under the impact of attempts to understand the analytical meaning and significance of this concept - and very much so in the process of transformation that this concept underwent - that the embryonic evolutionary theorizing in Marshall's work was suppressed" (Foss, 1991, p. 68).
} 
${ }^{35}$ Veja que no Livro VI, capítulo VII, o próprio Marshall (1890) admite que a lei de substituição "nada mais é do que uma aplicação especial e limitada da lei da sobrevivência dos mais aptos" (Marshall, 1890, p. 215).

${ }^{36}$ Nesse sentido, Hodgson (1993) é categórico: "For him diversity was more significant as the teleological result of the evolutionary process, rather than its essential starting point" (Hodgson, 1993, p. 61). ma interpretação spenceriana, pode ser entendido como o mecanismo pelo qual o princípio da continuidade, ou mudança gradual, se manifesta. Nesse sentido, numa visão que Spencer certamente aprovaria, Marshall (1890) combina a teoria do equilíbrio geral entre oferta e demanda com a ideia de continuidade com relação ao desenvolvimento. O Progresso, então, seria o resultado desse processo de mudança centrado na ideia de equilíbrio.

Sob essa visão entende-se que, ao recorrer à firma representativa, Marshall (1890) pôde, engenhosamente, dotar os princípios de continuidade e substituição de equivalência teórica aos princípios de mudança lamarckianos, ou seja, uma mudança gradual que procuraria um equilíbrio preconcebido. Essa perspectiva entende, portanto, que Marshall pôde absorver integralmente a ideia de Spencer de "Evolução" como Progresso em direção a uma heterogeneidade integrada.

O princípio de substituição adquire, nesse contexto, a mesma conotação spenceriana de "vassoura teleológica". Nesse sentido, Loasby (1990) e Thomas (1991) entendem que o conceito de substituição em Marshall pode ser entendido como uma aplicação do princípio de seleção spenceriano que, como vimos no tópico anterior, se centra na ideia de eliminação do imperfeito. ${ }^{35}$
Sob esse aspecto, a elaboração do conceito de firma representativa aparece como uma evidência de que Marshall (1890) se afasta completamente da ideia de processo evolucionário darwiniano, uma vez que, para esse código de ciência, a variação é o combustível da mudança, sendo essa o elemento central da constituição das populações. A firma representativa tem papel oposto à unidade darwiniana, ela é tipológica, invariável.

Por outro lado, encontramos em Spencer uma abordagem muito afeita à de Marshall acerca da variação. Em ambas as construçóes ela segue um caminho preconcebido dado por pequenas alterações em direção ao equilíbrio, sendo que as mudanças que se desviam desse caminho seriam eliminadas pela ação da seleção. Ao contrário da ideia darwiniana, na qual a variação e a seleção alimentam os processos de mudança, para Marshall e Spencer a variação é o resultado teleológico de uma teoria do progresso, ou seja, a culminação na heterogeneidade integrada. ${ }^{36}$

\section{4_Considerações Finais}

A compreensão dos caminhos que o pensamento evolucionário seguiu ao longo de sua história pode servir ao economista como um importante referencial para 
a construção de uma abordagem de "economia evolucionária” profícua.

O intuito desse artigo foi o de explicitar os resultados que podem ser obtidos a partir de uma abordagem que esteja atenta aos laços históricos que interligam a ideia de "economia evolucionária” e o desenvolvimento histórico do próprio pensamento evolucionário. Nesse sentido, o trabalho se restringiu à análise de um momento específico da era vitoriana, uma época tormentosa para o pensamento evolucionário, quando as teorias de Darwin e Spencer disputavam a primazia intelectual. Os diferentes conceitos de "evolução" expostos nos trabalhos de Darwin e Spencer nos fornecem, nesse sentido, elementos importantes para um olhar novo acerca dos Principles (1890).

Desta forma, pudemos identificar conceitos que muito se associam às ideias ditas evolucionárias de Marshall (1890), e constatamos que a perspectiva desse economista sobre os fenômenos da mudança socioeconômica se torna compatível com uma abordagem de traços spencerianos. Nesse sentido, o trabalho se centrou na ideia de mudança incremental e na visão de que todos os processos complexos seriam manifestações últimas de princípios físicos, sendo o equilíbrio seu fim preconcebido.
Buscamos assinalar, porém, que a "Evolução" de Marshall (1890) não deve ser entendida como uma mera repercussão do pensamento spenceriano nas ideias econômicas. Do ponto de vista aqui levantado, poderíamos assinalar que Marshall foi capaz de ressignificar o próprio mecanismo de transmutação spenceriano sem alterar seu resultado, substituindo, nesse caso, a ideia de mudança lamarckiana pelo cálculo diferencial, dando assim fundamentos estritamente matemáticos para o gradualismo. Nesse sentido, esse artigo nos dá pistas para a compreensão dos caminhos que Marshall seguiu para associar duas abordagens tidas hoje como significativamente incompatíveis: a evolucionária e a tipológica. Assim, assinalamos aqui que Marshall possui uma ideia de "Evolução" que, contrastando com a abordagem darwiniana, não se apresenta em contradição com uma perspectiva essencialista, afeita às ciências físicas. Se existiu uma "Evolução" para Marshall, ela era, assim como para grande parte dos vitorianos, gradual, melhorativa e equilibrista, ou seja, mais spenceriana que darwiniana.

Porém, é necessário assinalar de maneira veemente que buscar entender o caráter spenceriano dos Principles, sobretudo pela análise da concepção de progresso e de firma representativa, não 
esgota de nenhuma maneira a possibilidade de compreender a obra de Marshall através de um olhar darwiniano, como muitos autores vêm fazendo. Pelo contrário, entender como Spencer afetou as ideias de Marshall nos aponta os limites e as possibilidades de desenvolvimentos futuros de sua perspectiva econômica, a fim de contribuir com uma interpretação consistente de sua visão de "economia evolucionária".

Finalmente, queremos crer que nossa contribuição alcance um objetivo mais amplo do que a discussão sobre as influências de Spencer e Darwin sobre Marshall. Procuramos apresentar um possível caminho para o desenvolvimento de uma abordagem de "economia evolucionária" que esteja ligada e mantenha uma referência constante aos debates históricos do próprio pensamento evolucionário, um trabalho ainda por ser feito. 


\section{Referências bibliográficas}

ALVEY, J. (1987). Some Thought on the Philosophical and Value Assumptions underlying Marshall's Principles of Economics. Macquire University School of Economic and Financial Studies, Research paper n. 317.

ASPERS, P. (1999). The Economic Sociology of Alfred Marshall. American Journal of Economics and Sociology, v. 58, n. 4 , p. 651-667.

BAIARDI, D. (2008).

Conhecimento, Evolução e Complexidade na Filosofia Sintética de Herbert Spencer. Dissertação de Mestrado. Faculdade de Filosofia e Ciências Humanas, USP.

CARNEIRO, R. L. (1973).

Structure, Function, and

Equilibrium in the Evolutionism of Herbert Spencer: Journal of Anthropological Research, v. 29, n. 2, p. 77-95.

DARWIN, Charles. (1859). A Origem das Espécies. São Paulo: Martin Claret.

DAWKINS, R. (2008). The Oxford Book of Modern Science Writing. Oxford: Oxford University Press.

DENNET, Daniel C. (1995). A Perigosa Ideia de Darwin. Rio de Janeiro: Rocco.
DENNET, Daniel C. (2006). The Selfish Gene as a Philosophical Essay. In: GRAFFEN, A; RIDLEY, M. (2006). Richard Dawkins: How a Scientist Changed the Way We Think. Oxford: Oxford University Press.

FISHBURN, G. (2004). Natura non facit saltum in Alfred Marshall and Charles Darwin. History of

Economics Review, n. 40, 60-68.

FOA, B. (1982). Marshall revisited in the Age of DNA. Journal of Post Keynesian Economics, v.5, n. 1, p.3-16

FOUCAULT, M. (1966).

As Palavras e as Coisas: Uma arqueologia das ciências. São Paulo: Martins Fontes.

FOSS, J. N. (1991). The Suppreion of Evolutionary Approaches in Economics: The Case of Marhall and Monopolistic Competition. Methodus, dezembro, 65-72

FOSS, J. N. (1994). The Biological Analogy and the Theory of the Firm: Marshall and Monopolistic Competition. In: HODGSON, Geoffrey M. (1998) The Foundations of Evolutionary Economics: 1890-1973.

Cheltenham: Edward Elgar.
FOSS, J. N. (1996). Thorstein B. Veblen: Precursor of the Competence-Based Approach to the Firm. DRUID Working Paper, v. 15, n. 96 , novembro.

FREEMAN, Derek (1974). The Evolutionary Theories of Charles Darwin and Herbert Spencer. Current Anthropology, v. 15, n. 3, p. 211-237.

GALBRAITH, J. K. (1977). A Era da Incerteza. São Paulo: Pioneira

GLASSBURNER, Bruce. (1955). Alfred Marshall on Economic History and Historical Development. The Quarterly Journal of Economics, v. 69, n. 4, p. 577-595.

GOULD, Stephen J. (1982). Introduction. In: DOBZHANSKY, Theodosius. (1937). Genetics and the Origin of Species. New York: Columbia University Press.

GUILleBAUD, C. (1942). The Evolution of Marshall's Principles of Economics. The Economic Journal, v. 52, n. 208, p. 330-349.

GROENEWEGEN, P. (1995). $A$ Soaring Eagle: Alfred Marshall 1842-1924. Hants: Edward Elgar.

HAINES, V. A. (1988). Is Spencer's Theory an Evolutionary Theory? The American Journal of Sociology, v. 93 , n. 5, p. 1200-1223.
HAINES, V. A. (1992). Spencer's Philosophy of Science. The British Journal of Sociology, v. 43, n. 2, p.155-172.

HAMMOND, J. (1991). Alfred Marshall's Methodology. Methodus, junho, 95-101.

HISKES, R.P. (1983). Spencer and the Liberal Idea of Community. The Review of Politics, v. 45, n. 4 , p. 595-609.

HODGSON, G. (1993). The Mecca of Alfred Marshall. Economic Journal, v.103, p. 406-15.

HODGSON, G. (1998).

Introduction. In: HODGSON, Geoffrey M. (1998) The

Foundations of Evolutionary

Economics: 1890-1973.

Cheltenham: Edward Elgar.

HODGSON, G. (2001). How Can Evolutionary Economics Evolve? In: ARUKA, Y. (2001). Evolutionary Controversies in Economics. New York: Springer.

HODGSON, G. (2004). Darwinism, Causality and the Social Sciences. Journal of Economic Methodology, v. 11, n. 2, junho, p. 175-194.

HUXLEY, Julian. (1940). Darwin. In: Biblioteca do Pensamento Vivo. Sáo Paulo: Martins Editora. 
JABLONKA, Eva; LAMB, Marion J. (2005). Evolution in Four Dimensions. Cambridge: The Massachusetts Institute of Technology Press.

KEYNES, J. M. (1924). Alfred Marshall, 1842-1924. The Economic Journal, v. 34, n. 135, p. 311-372.

LA VERGATA, A. (1995). Herbert Spencer: Biology, Sociology, and Cosmic Evolution. In: HODGSON, G M (1998) The Foundations of Evolutionary

Economics: 1890-1973.

Cheltenham: Edward Elgar.

LEAKEY, Richard. (2007).

Introdução. In: DARWIN, Charles. (1859). A Origem das Espécies. São Paulo: Martin Claret.

LEÃO, I. C. (2001). Notas Sobre Marx, Darwin e o

Progresso. Economia e

Sociedade, n. 16, p. 141- 145.

LÉVI-STRAUSS, C. Claude (1962).

O Pensamento Selvagem. São Paulo: Papirus.

LEVINE, A. (1983). Marshall's Principle and the "Biological Viewpoint": A Reconsideration. Manchester School of Economics and Social Studies, v. 51, n. 3, p. 276-93.

LOASBY, B. (1986). Marshall's Economics of Progress. Journal of Economic Studies, v.13, n. 5, p.16-26.

LOASBY, B. (1990). Firms, Markets, and the Principle of Continuity. In: WHITAKER, J. (1990). (Org.). Centenary Essays on Alfred Marshall. Cambridge: Cambridge University Press.
LUZ, M. R. S; FRACALANZA, P. S. (2010). Da Te(le)ologia ao Evolucionário: $\mathrm{O}$ legado essencialista e a possibilidade darwiniana de teorização econômica. In: Anpec, 38, 2010, Salvador. Anais Salvador.

MARSHALL, A. (1885). The Present Position of Economics. In: PIGOU, A. C. (1925). Memorials of Alfred Marshall. Londres: Macmillan.

MARShall, A. (1890). Princípios de Economia. São Paulo: Abril Cultural.

MARSHALL, A. (1898). Mechanical and Biological Analogies in Economics. In: PIGOU, A. C.(1925). Memorials of Alfred Marshall. Londres: Macmillan.

MAYR, E. (1982). The Growth of Biological Thought. Cambridge: The Belknap Press of Harvard University Press.

MAYR, E. (2000). Darwin's Influence on Modern Thought. Scientific American, julho, p. 79-83.

MAYR, E. (2006). Uma Ampla Discussão. Charles Darwin e a Gênese do Moderno Pensamento Evolucionista. Ribeirão Preto: FUNPEC Editora.

MOSS, L. (1982). Biological

Theory and Technological Entrepreneurship in Marshall's Writings. Eastern Economic Journal, v. 8, n. 1, p. 3-13.
MOSS, L. (1990). Evolutionary Change and Marshall's Abandoned Second Volume. Economie Appliquée, v. 43, n. 1 , p. $85-98$

NELSON, Richard. (1995). Recent Evolutionary Theorizing About Economic Change. Journal of Economic Literature, v. 1, n. 33, março, p. 48 -90.

NELSON, Richard; WINTER, Sidney G. (1982). Uma Teoria Evolucionária da Mudança Econômica. Campinas: Editora Unicamp.

PARSONS, T. (1932). Economics and Sociology: Marshall in Relation to the Thought of his Time. The Quarterly Journal of Economics, v. 46, n. 2, p. 316-347.

PERRIN, R. G. (1976). Herbert Spencer's Theories of Social Evolution. The American Journal of Sociology, v. 81, n. 6, p. 1339-1359.

PIGOU, A. C. (1928). An Analysis of Supply. Economic Journal, n.

38 , p. $238-257$

POPPER, K. (1950). A Sociedade Aberta e Seus Inimigos. Belo Horizonte: Livraria Itatiaia Editora Ltda.

REISMAN, D. (1987). Alfred Marshall, progress and politics. Londres: MacMillan.

SCREPANTI, E.; ZAMAGNI, S. (2005). An Outline of the History of Economic Thought. New York: Oxford University Press.
SOBER, Elliot (1980). Evolution, Population Thinking and Essentialism. Philosophy of Science, v. 47, n. 3, p. 350-383.

SPENCER, H. (1851). Social Statics. London: Routledge

SPENCER, H. (1857).

Do Progresso: Suas Leis e Suas

Causas. Lisboa: Inquerito.

SPENCER, H. (1862). First Principles. London: Routledge.

STAVELEY, R. ALVEY, J (1988). The Philosophical Assumptions Underlying Marshall's Economics. In: WOOD, J.(1988). Alfred Marshall Critical Assessments. London: Routledge.

TAYLOR, M. (1996). Introduction. In: TAYLOR, M. (1996). Herbert Spencer: Contemporary Assessments. London: Routledge.

TAYLOR, M. (1996a).

Introduction. In: SPENCER, H. (1862). First Principles. London: Routledge.

THOMAS, B. (1991). Alfred Marshall on Economic Biology. Review of Political Economy, v.3, n. 1, p. $1-14$

VEBLEN, Thorstein. (1898). Why is Economics not an Evolutionary Science? The Quarterly Journal of Economics, v. 12, julho, p. 373-397.

VEBLEN, Thorstein. (1904). Teoria da Empresa Industrial. São Paulo: Editora Globo.

VEBLEN, Thorstein. (1906). The Place of Science in Modern Civilization. The American Journal of Sociology, v. 11, n. 5, março, p. 585-609. 
WHITAKER, J. (1990). What Happened to the Second Volume of the Principles?. In: WHITAKER, J.(1990). (Org.) Centenary Essays on Alfred Marshall. Cambridge: Cambridge University Press.

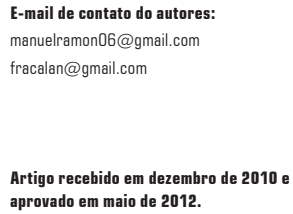

